infant between 2008 and 2012. The Nova Scotia Atlee Perinatal Database was used to determine socio-demographic characteristics and pregnancy conditions. Spatial estimates of air pollution were determined from land-use regression (LUR) models and were linked to women in the Perinatal Database based on their six-digit postal code. Residential concentrations of sulfur dioxide $\left(\mathrm{SO}_{2}\right)$, nitrogen dioxide $\left(\mathrm{NO}_{2}\right)$, particulate matter $\left(\mathrm{PM}_{1}\right.$, $\mathrm{PM}_{2.5}, \mathrm{PM}_{10}$ ), toluene, and benzene were averaged over three seasons and categorized into quartiles. Odds ratios (OR) and $95 \%$ confidence intervals (CI) were calculated using logistic regression, adjusting for potential confounders.

Results Of the 11,724 singleton births analyzed, $7.7 \%$ of the cohort developed $\mathrm{GH}$. When adjusted for smoking, prepregnancy weight, maternal age and parity a significant inverse relationship was observed for exposure to all pollutants (top quartile of exposure relative to lowest quartile); $\mathrm{SO}_{2}$ (OR: 0.75 ; 95\% CI: 0.62, 0.92), $\mathrm{NO}_{2}(0.66 ; 0.54,0.81), \mathrm{PM}_{1}(0.71 ; 0.57$, 0.87), $\mathrm{PM}_{2.5}(0.68,0.56,0.83), \mathrm{PM}_{10}(0.71 ; 0.58,0.87)$ toluene $(0.68 ; 0.56,0.83)$ and benzene $(0.62 ; 0.51,0.75)$.

Conclusion The inverse relationships observed were contrary to what has been observed in past research. These results stress the importance of conducting more research in this field to better understand the characteristics that influence the relationship between air pollution and GH.

\section{ASSOCIATIONS BETWEEN EXPOSURE TO AIR POLLUTION AND GESTATIONAL HYPERTENSION IN URBAN HALIFAX}

A Poirier, ${ }^{1}$ L Dodds, ${ }^{2}$ M Johnson, ${ }^{3}$ T Dummer, ${ }^{4}$ D Rainham ${ }^{5}$. 'Department of Community Health and Epidemiology, Dalhousie University; ${ }^{2}$ Perinatal Epidemiology Research Unit, Department of Obstetrics and Gynecology, Dalhousie University; ${ }^{3}$ Air Health Science Division, Health Canada; ${ }^{4}$ School of Population and Public Health, University of British Columbia; ${ }^{5}$ Departments of Sustainability and Environmental Science, Dalhousie University

\subsection{6/jech-2014-205217.5}

Introduction Exposure to air pollution has been linked with an increased risk for cardiovascular morbidity and mortality. Few studies have examined possible associations between air pollution and gestational hypertension $(\mathrm{GH})$. The prevalence of $\mathrm{GH}$ in Canada is approximately $6 \%$, translating into roughly 300 women developing $\mathrm{GH}$ in Halifax annually. $\mathrm{GH}$ disorders account for $2-8 \%$ of pregnancy complications worldwide.

Objective The current study examined the relationship between exposure to air pollution during pregnancy and GH.

Methods A retrospective cohort study including women residing in urban Halifax, Nova Scotia who delivered a singleton 